\title{
INCORPORATING CLIMATE SCIENCE INTO DISASTER MANAGEMENT PROGRAMS
}

\author{
ELEONORE (NORA) D. YOTSOV \& DOUGLAS C. STOLZ \\ Port of Portland and Cross Product Atmospheric, LLC, USA
}

\begin{abstract}
Human action (sometimes inaction) creates vulnerabilities that expose populations to impacts from disasters. The effects, especially those stemming from attributing factors such as climate change, are not often directly perceptible or understood in the context of disaster. These impacts are the most challenging to address and at the same time present an opportunity for increasing effectiveness of disaster risk reduction measures. There is much work to be done to reduce the gap between the science of climate change and disaster management. Such barriers to application include (but are not limited to) the nebulous nature of climate change itself, the perceived lack of value of prevention efforts through upfront investment and the burden whereby climate change and also the need to act now is fraught in partisan political process. There is a critical need to overcome these barriers, as the emergency response and recovery efforts are currently unable to keep up with increasing and ever worsening impacts from disasters. As humans develop and learn new information, there is often a delay between initial sense making and learning to acceptance and enculturation. There are four key steps for incorporating climate change science into the disaster risk reduction arena: 1) seek out unbiased scientific information; 2) understand the impacts and implications to develop accurate risk perception for the population; 3 ) reduce the existing gap by translating the science and engaging the appropriate stakeholders; and 4) apply this initiative through existing opportunities and innovations. Through history of the disaster management profession, the areas of concern expand as civilizations become more complex, interconnected and dependent on anthropogenic solutions. These impacts will only increase humanity's actions (or inactions), augmenting collective exposure and vulnerability. Understanding how current and future impacts increase vulnerability in concert with other conditions can allow the development of truly multi-disciplined disaster risk strategies.
\end{abstract}

Keywords: climate change, adaptation, disaster management, risk assessment, vulnerability, hazard, mitigation, Cuba, Tarea Vida.

\section{INTRODUCTION}

Today, there is no doubt that impacts to humanity from natural disasters are increasing leaving reliance on response and recovery insufficient and ineffective to adequately manage the trend. There are a variety of factors that contribute to this including population growth, social inequities such as poverty and health, increasing development in vulnerable areas, reliance on technological advances that promote protection from natural hazards based on old/inadequate data and so on.

Disaster Risk Reduction (DRR) has come to the forefront as the mechanism aimed at reducing the impact of disaster to a specific population through a series of actions embedded in the disaster management field. Incorporating climate science into DRR has been a challenge and siloed effort to date. Even though there are calls by many academics and practitioners in the field, over the past 30 years, climate change adaptation (CCA) knowledge and DRR have been mostly separate and somewhat parallel paths. Climate science provides needed knowledge to help disaster managers understand cause and effect in order to more effectively plan for and respond to situations. Not unlike the science of seismology or volcanology, climate science is a tool that is underutilized, if utilized at all, by the disaster management community. Dr. Ilan Kelman proposes that climate change should be a subset of disaster risk reduction "Rather than keeping climate change as a separate or dominating 
topic, the proposal from a development perspective is to enact the 'multiple exposure' perspective by viewing climate change as one challenge amongst many" [1], [2].

Examples of development in flood zones, tsunami inundation zones, remote areas and climates not naturally able to sustain humanity are still occurring. Climate change contributes to disasters by creating conditions that can amplify the magnitude of quick onset storms, but also in creating longer duration changes that transform the environment where pre-established practice is no longer adequate. The challenge of relating climate change impacts to specific disasters is mired in politics and interacts with a variety of other factors that can mask or derail appropriate attribution. This paper addresses the need, provides a real-world example and highlights four key steps for incorporating climate science into disaster management programs.

\subsection{Potential harm in neglect - NFIP as an example}

The National Flood Insurance Program (NFIP) in the United States is a useful example of a well-meaning method that has created more vulnerability, due to its method of addressing a single hazard instead of including all contributing factors. The NFIP was established over 50 years ago to protect the public through insurance backing to provide financial assistance for those with limited resources recovering from floods. Rather than protect, the program created more vulnerability by allowing new development and people with financial constraints to stay in flood prone areas using risk transference rather than looking at all contributing factors related to flooding hazards. Using out-dated and inaccurate flood maps created more risk by allowing development and repetitive repairs for damaged homes, rather than looking into other drivers of floods. As a result, increases in payouts due to increased flooding and repetitive flood loss, the program has become insolvent.

The Biggert-Waters Flood Insurance Reform Act of 2012 was enacted to raise premiums to increase reflecting the "true risk" of living in high-flood areas in an effort to bail out the NFIP [3]. The U.S. Government Accountability Office (GAO) has placed the NFIP in its high-risk list. This is a result of NFIP's worsening debt in response to growing disasters and the increase in rates for homeowners who benefited from previously subsidized rates that did not previously reflect "full risk of loss". This burden falls squarely onto those who it was meant to protect [4].

In this simple example, looking at climate trends can help inform future development and limit rebuilding efforts before and after floods. While the GAO report focused on improving programmatic elements such as debt reduction, affordability and barriers to involvement, the outstanding issue is the evolving environment where development is allowed to continue. Incorporating relevant climate science information is key to understanding how the changing natural hazard risk profile will affect the human condition.

\section{ADVANCES IN DISASTER MANAGEMENT}

The field of Emergency or Disaster Management has made tremendous advances and evolved from a single focus fire response function to a multi-hazard professional field. In the simplest terms "emergency management is the discipline dealing with risk and risk avoidance." Traditionally a government function, in the United States this field had its start following a devastating fire in 1803 and has evolved into an all-hazards approach including all natural and manmade disasters [5]. Disaster Management has evolved from a fire response to a civil defence function focused on nuclear threats from the cold war, to expanding to natural disasters in the 1960s to the inclusion of terrorism post 2001 and today to including seismology and volcanology as pre-emptive tools to address potential hazards. 
Internationally, the field includes response, recovery, finding overlap in the related fields of development, planning and humanitarian aid, where adaptation and mitigation strategies complement the similar strategies employed in disaster management.

Since Disaster Management is such a broad profession that has grown to encompass not only historical data to inform risk reduction, but also predictive modelling, assimilating relevant aspects of emerging climate science is a necessary and logical progression. Allowing for siloes to exist is no longer viable and potentially irresponsible if DRR efforts are to continue being effective.

\subsection{Seismology and volcanology to inform}

In the Pacific Northwest, for communities along the ring of fire, the science of seismology is rapidly being incorporated into Disaster Management practice. In only in the last 30 years, a deeper understanding of potential Cascadia Subduction Zone magnitude 9.0 earthquake impacts [6] has provided impetus for investment into development, mitigation and other related strategies. These efforts are varied and include seismically retrofitting critical infrastructure such as key bridges and the Critical Energy Infrastructure (CEI) Hub [7] as well as investment into earthquake early warning systems, such as the ShakeAlert system for the West Coast of the United States [8].

Similarly, the Pacific Northwest has a geographical distribution of volcanoes, whose hazards vary, but are also addressed through proactive methods, such as alert and warning and protection measures, such as evacuation planning [9].

The acceptance of seismology and volcanology has dynamically evolved the field of Disaster Management for communities at risk in the Pacific Northwest. By seeking out and understanding the science, disaster managers, with the assistance of the scientific community and subject matter experts have been able to translate and apply the science into effective practice to accurately address risk and proactively take action.

\subsection{Displacement's increasing impact}

Disaster impacts are categorized in many ways, including, but not limited to direct and indirect toll on humanity, economic loss to infrastructure, social and natural resources loss, and so on. Displacements from natural disasters are becoming more frequent and there is great interest in determining possible links to climate change - whether changing climate affects the magnitude and probability of occurrence of individual natural hazards [10]. The relatively short global observation record of extreme events as well as statistical methods used to assess attribution likelihood preclude a determination until after the event has occurred. Southeast Asia is highly prone to natural disasters, which are exacerbated by high population vulnerabilities and reliance on natural resources. In this region, those populations with some of the lowest known socioeconomic standing are situated in one of the more active tropical cyclone and riverine/inundation flood zones in the world; there is general scientific consensus that these natural phenomena will become worse/more intense in the coming decades and meanwhile rural southeast Asian populations are some of the least well equipped and apt to respond in disaster scenarios.

Still, DRR advances since the 1970s have provided protection mechanisms for many vulnerable populations in the face of natural disasters. While much work of DRR has protected lives, displacement (temporary, protracted or permanent) has been an increasing trend. Tracking disaster related displacement data started in 2008 by the Internal Displacement Monitoring Centre (IDMC). Since then, the toll displacement not only for the 
victims, but also host communities was largely understudied or unknown. Understanding the breadth of displacement from direct natural disaster, as well as indirect ecological change brought on by slow-onset climate driven forces, can inform disaster managers to proactively address these hazards.

In 2018, according to the IDMC, almost two thirds of the new displacements (not including protracted or permanent), an estimated 17.2 million are a result of disaster as compared to conflict [11]. Climate change can be a force multiplier for natural disasters, which increases the opportunity for displacement, thus creating cascading disasters, for not just those displaced but also host and aid communities tasked with caring for those displaced. Harnessing climate science, not just for CAA but also for DRR can be a valuable source of information advising proactive and prevention measures.

\section{ADVANCES IN CLIMATE SCIENCE}

\subsection{Background}

It is instructive to distinguish between weather and climate in a simple manner up front: weather is the specific atmospheric condition at a given place and time, whereas climate science deals specifically with variations and interactions in Earth's atmosphere, oceans, cryosphere, and biosphere over distances of up to approximately $10,000 \mathrm{~km}$ spatial scales and multiple decades. As such, society easily conceptualizes how day-to-day weather changes impact daily life and operations. In contrast, it is considerably more difficult for the average person to perceive changes in climate over weeks, months or even multiple years, and furthermore, how those very changes directly (and possibly indirectly) affect their livelihoods. In fact, there exists a rich history of climate research and applied operational development that has established a vast climate-science resource base. What follows next is an reasonable cross-section of presently available climate science references, including operational data and modelling systems, services and service providers, as well as information pathways that may be consulted by practitioners (referred to as, "climate information") [12] seeking to develop robust climate mitigation and adaptation strategies to be applied within the field of disaster management.

\subsection{Types of climate information}

Climate information that may be useful to Disaster Risk Reduction specialists can be loosely classified as historical records, future projections, and synthesized reports. For example, observations from tree rings, ice cores, coral reef deposits, subterranean bore holes in Arctic permafrost and multi-decadal air samples provide evidence of a changing climate. These types of data may be analyzed in specific ways to determine the extent of potential impacts on human life, property and infrastructure (depending on the source, these data are usually freely available to the public). In addition, such observations serve as a critical input for another form of climate intelligence - numerical climate models - which themselves are founded on the idea that current conditions can serve as the basis for future prediction of general circulation and regional temperature/precipitation patterns, etc. Finally, in the modern era of data proliferation and near-instantaneous digital communications, the general public is seemingly inundated with excess of climate information. Fortunately, both private and public entities as well as multi-national government-sanctioned agencies exist and work to consolidate and collate available research, data and documentation into concise reports for interested parties. 


\subsubsection{Authoritative sources of climate information}

Many organizations around the world, each possibly operating at different bureaucratic levels, work collectively to address outstanding gaps in climate information delivery, essentially to inform possible gaps that exist between climate science development and practice. At the international level, the World Climate Research Program (WCRP) drives advancement in climate predictions by facilitating technical climate model intercomparison [13] as well as professional scientific workshops and conferences. The Intergovernmental Panel on Climate Change (IPCC) [14] is a body of the United Nations tasked with assessing the state-of-the-science related to climate change; the IPCC publishes its assessments periodically and meanwhile they are oft-cited in technical/policy proceedings and revered as the gold-standard of scientific climate information. Similarly, the United States (U.S.) National Research Council routinely publishes the National Climate Assessments, the most recent being the 2018 version [15], and within these pages one can gain access to regionalized climate insights and climate mitigation/adaptation strategies.

In the operational setting and using the U.S. as an example, the National Centers for Environmental Information's Climate Prediction Center (CPC) provides routine climate information updates (monthly and in some cases more frequently). Much of this information from the CPC is effectively summarized for general climate science [16] and hurricanes [17] for both situational awareness and educational purposes. Analogous organizations exist within the European Union - like the European Centres for MediumRange Weather Forecasts (ECMWF) [18] - and they provide products that essentially cleanse, collate, and organize atmosphere/ocean observations over many decades for reference (i.e., "re-analysis"). Regional U.S. climate centers [19] exist to identify and develop sector-specific materials suitable for application in certain regions of interest. Furthermore, the U.S. National Weather Service's forecast offices maintain their own suite of climate information for localities and observation stations near critical assets and key resources.

Academic and private sector agencies provide additional subject-matter expertise and value-adding insight. Laboratories in the U.S. like the Earth Systems Research Laboratory (ESRL) house targeted research working groups, like the Physical Science Division at ESRL [20], who develop cutting-edge climate science and improve understanding of climate extremes and cascading impacts to society. Joint research institutes cultivate actionable climate information for global stakeholders; findings from their research are commonly published in the scientific peer-review literature supported by the American Meteorological Society and American Geophysical Union, etc. Lastly, organizations in the private sector develop agile, industry-specific climate information solutions that can leverage the latest innovative technologies (e.g., artificial intelligence/computer learning software) and they commonly provide these products as a service to consumers.

\subsubsection{Aside on data and access}

Underlying all of these sources of climate information is an enormous amount of data from computer calculations and Earth-observation platforms (which can also be utilized to "scale down" and drive specialized models of flood/storm surge/precipitation extremes or regional temperature, for example). Many, though not all, of the aforementioned authorities on climate science information will provide transparent access to their data as well as software that is designed for quick access and visualization. Collaborating with someone who is trained in the physical sciences and well-versed in technical computing is recommended, as these data are commonly archived in non-standard data formats. The trend is hosting digital data resources in web-enabled user interfaces and cloud-based data archives, thus supporting truly global information sharing for those with reasonable means of internet access [21]. 


\subsubsection{On properly interpreting "climate information"}

The urgent operational need for climate guidance should be reasonably tempered by understanding of underlying issues that affect climate information development - chief among them is uncertainty. We know from experience that the science of weather and climate prediction is imperfect, which we recognize anecdotally as differences between what was forecast vs. that which was observed for a given location, time, or even season. It is beyond the scope of this paper to detail sources of uncertainty [22], but it stems from our inability to accurately and precisely measure conditions everywhere with sufficient granularity to inform future predictions. In addition, characterizations of governing physical processes and Earth-system responses (i.e., feedbacks) to anthropogenic inputs and/or changes, are simplistic by assumption and therefore do not fully explain the process or phenomenon.

Bearing the above in mind, it is true that advances in computer technology aid in the effort to improve timeliness, accuracy, and precision in climate prediction, but the realization of a "perfect prediction" of climate is not likely to happen. Considerable effort in the field of weather and climate prediction is being focused on the optimal means to communicate predictions along with associated error in the most effective way possible. What this means is that triggers or thresholds for action will be based on, hypothetically for example, a 6-in-10 chance of above-normal temperatures occurring in the next 4-6 weeks somewhere within an area of 25 miles from a given location. How this type of climate information is then incorporated within emergency action plans will require inputs from subject matter experts or those that have some background experience with climate, atmospheric, and/or the Earth sciences.

\subsection{Future implications for disaster management}

We are generating climate information at unprecedented rates and volumes in the modern age, thereby increasing the prospects of improved accuracy and precision in climate forecasts out to several decades or more. New techniques to handle, visualize, conceptualize, and interpret this ever-growing stream of scientific intelligence for the growing base of practical consumers will be needed. To match, the science of Disaster Risk Reduction will continue to develop and support greater integration of climate information in practice. Greater spatial resolution, longer, and more-accurate climate forecasts may be the key to support breaking out risk mitigation/climate adaptation, even by hazard or at a very local level.

\section{FOUR KEY STEPS AND CUBA'S TAREA VIDA}

As human development learns new information, there is often a delay between the initial encounter, learning, acceptance, adoption and subsequent enculturation. There are four key steps for incorporating climate change science into the disaster risk reduction arena. Each step is listed with an example of how it was accomplished via Cuba's state strategy.

Cuba's efforts result in minimal loss of life compared to other countries in the hurricane prone Caribbean. While Cuba is considered a developing country with well-documented struggles, limited resources and infrastructure, Cuba is one of the most resilient countries in the Caribbean. So, what sets them apart from Puerto Rico, Haiti or the Dominican Republic?

Cuba's recognition of climate change impacts to humanity dates back nearly 30 years with a speech by Fidel Ruz Castro at the 1992 Earth Summit in Rio de Janeiro, Brazil. This has driven many of Cuba's efforts to address the growing hazards and to reduce vulnerabilities. "Climate change is one of the greatest challenges of these times, unleashing such phenomena as sea level rise, temperature upticks, extreme hydro-meteorological events, seasonal changes in rainfall rates, severe droughts and intense rains. If the mindset on this is not changed and 
dramatic measures are not taken, the future will not only hold a more expensive side, but it will also become more difficult for human survival in the face of these effects" [23]. With this in mind, Cuba set out to incorporate climate science into its disaster risk reduction strategies through a variety of policy and practitioner mechanisms.

Tarea Vida (Life Task) was approved on April 25, 2017, but had its start in 1991. Tarea Vida is the state plan for confronting climate change based on a multidisciplinary scientific basis. The plan prioritizes nearly half of its municipalities in the coastal and territorial areas that are most at risk from climate change magnification to natural disasters. It is comprised of five strategic actions and eleven tasks to proactively address impacts of climate change and protect its people. "The project will provide support in transitioning from hard disaster risk management approach to $\mathrm{CC}$ to a holistic approach that favors resilience through adaptation as a continuous process that maximizes the functionality of natural infrastructure along coastal zones and that is grounded on and sustained through coastal communities and informed coastal planning mechanisms" [25].

\subsection{Seek}

Seek out unbiased scientific information. As discussed above, climate science information is a readily available in multiple forms and to serve as an accessible resource for Disaster Management/DRR. While the body of knowledge can be overwhelming and excessively technical, there are multiple pathways of gathering this new information via online resources, in print, and via documentaries.

As with any new science, there is a period of time before a body of work can be absorbed into common knowledge and practice, meanwhile recognizing the importance of building relationships and opening dialogue channels between science groups and those who operate solely as practitioners. Cuba's tendency to consult available scientific resources is well documented. As a country with a ratio of 7.5 physicians per 1,000 people, the use of science and technology to inform policy has a long history in Cuba dating back to the pre-founding of the country [26]. Incorporating science into policy and practice has been key, even under the financial and political constraints within the country.

The Institute of Meteorology's (INSMET) role in prediction, alerting and warning is key to protecting the population. Serving in leadership roles in the World Meteorological Organization, Cuba's INSMET has a structured methodology that is well known and followed throughout the country. With offices in each province and some larger cities, INSMET provides a phased warning approach. Early warning is 72 hours in advance, followed by Special warning 66 to 48 hours in advance to be followed with localized evacuation and protection warnings, where necessary [27]. Utilizing scientific data from INSMET is only one example of how to effectively seek out scientific information.

\subsection{Understand}

Understand the impacts and implications to develop accurate risk perception for the population. Knowing how much each contributing factor is truly influencing disasters provides a better understanding of future mitigation and adaptation measures. Simplifying to either deny or attribute an entirety of an event to climate change impacts does not accurately help disaster managers understand what factors need to be addressed. In contrast, understanding the frequency of occurrence, maximum possible extent of affected area, and severity of events (as well as how they are measured and characterized officially) are useful lenses through which to contextualize natural hazards. Further effort should be directed 
towards comprehending how multiple natural hazard events occurring at once can create cascading impacts and how those hazard interactions might evolve in a changing climate.

Climate science is included at all levels of education throughout the Cuba school system, not only at the university levels, but starting at grade school. Climate information is included in various UNDP programs that operate in provinces with special focus to the specific risks. Understanding increased climate variability and trends, the Cuban government, UNDP Cuba and UNDP's Caribbean Risk Management Initiative (CRMI) created the Risk Reduction Management Center (RRMC) model. "At the heart of the model is the promotion of local level decision-making that relies on coordinated early warning systems, risk and vulnerability studies, communications systems, effective database management and mapping, GIS, and community preparedness." There are 8 provincial and 84 municipal centers. The RRMC are established to focus on localized hazards and vulnerabilities, for example, the RRMC in Santa Cruz del Sur focuses on hurricanes, flooding and storm surges, etc., while the RRMC in Santiago de Cuba additionally focuses on droughts and fires and technological hazards [28].

The general public has conceptual understanding of protection categories specific to evacuation for their location. First priority is to transfer people to lower risk and structurally safer areas in a bid to protect their safety. Second priority is to evacuate people to designated facilities including public buildings, tunnels, caves and even "vara en tierra" (traditional huts). In the city of Gibara, evacuation to the cave system outside of town is accepted practice and helped save lives when the entire town was evacuated during Hurricane Ike in 2008 [29].

\subsection{Translate}

Reduce the existing gap by translating the science and engaging the appropriate stakeholders. In order to effectively create programmatic elements, input from a variety of subject matter experts across multiple disciplines, such as climate science, computer science, urban planning, civil engineering, and sociology/psychology are necessary. Emphasis for such collaboration is on strengthening an all-hazards approach programs to better understand cause and effect relationships.

Since 1986, Cuba annually conducts a nationwide full-scale exercise that includes all members of government, civil society and individual members of the population. The exercise is compulsory in nature from the top down. The "Meteoro" exercise happens in May and aims at exercising all elements of hurricane response, protection, evacuation and recuperation elements. The timing of the exercise is in preparation for the hurricane seasons (June-November each year). Tarea Vida's tasks are another example of how climate science is translated into action. According to Rolber Reyes Pupo with CITMA, in Gibara alone, the following disaster risk reduction actions were taken in advance of the next hurricane [30]:

- Removal of 15 homes located in areas vulnerable to sea level rise and coastal flooding (funding for relocation strategies can be hard to come by).

- Ovidio Torres elementary school and the local hospital moved to safe places.

- New road built to link Caletones and Gibara through the settlements of Las Caobas, El Macio and Laguna Blanca aimed to reduce their coastal hazards.

- Recovery of mangroves, dunes and sand and coastal reefs as natural protection barriers.

\subsection{Apply}

Apply this initiative through existing opportunities and innovations. There are many pathways for disaster management, but the best approach is through the practice of DRR. Using projections from available climate models to inform sea-front infrastructure 
development/refurbishment design or revising existing hazard mitigation plans to include updated thresholds and triggers are basic examples of applied climate science in action.

How are these efforts applied in the case of Cuba's activity? The true application is in the ability to more effectively protect the public during hurricanes. So how does this occur? The process has been enculturated so that when there is warning of an impending hurricane, overall the population responds with well known, practiced and accepted methods. The cultural shift that occurs from the previous 3 steps, is proven in application through the relatively low mortality rate of Cuba's hurricanes vs. other Caribbean island nations, or even first world nations, like the United States.

During Hurricane Ike, Cuba conducted evacuations and protective measures for over 2.6 million people and experienced 7 direct fatalities [24]. In the United States where over 200,000 refused evacuation orders and of the 195 who died in the US, 113 alone were in Texas. Retrospective studies of communities affected by (major) hurricanes contribute that societal risk perceptions of natural hazards are often acutely related to imminent environmental cues (e.g., increasing winds and rising water levels), but also to social cues, warning messaging, and personal preference or inherent risk tolerance; these factors collectively lead behavioral response and protective-decision making [31]. Nearly $30 \%$ of respondents to a post-hurricane Ike inquiry cited the highest importance level of peer communications in evacuation decision making [32], thus alluding to the importance of enculturated disaster preparedness practice. In Cuba, strong social networks work in tandem with well-practiced and accepted methods.

\section{DISCUSSION}

We recognize that socioeconomic, political, geographical, or even other artificial barriers might need to be overcome as part of risk reduction initiatives geared to the dynamic, natural process of climate change. A main goal of this paper is to establish that disaster risk reduction principles and climate science information can be leveraged simultaneously to promote better outcomes while constantly grappling with ever-changing community-wide risk factors and vulnerabilities. To mitigate some of that uncertainty, an effective general framework could involve the steps of 1) seek, 2) understand, 3) translate, and 4) apply information in practice. Using Cuba's Tarea Vida as a quintessential example, successful mitigation practice arises from widespread acknowledgment of the impact of climate change and subsequent enculturation of the ideals of disaster risk reduction.

It is possible that availability, accessibility and applicability climate science information will co-evolve with the burgeoning field of disaster risk reduction. In a perfect world, dialogue between practitioners and scientists will become more common place; such open discussion could see practitioners express their targeted needs for guidance and science experts reciprocating by informing practitioners of the current state-of-the-art in addition to providing distilled meaning of available climate science information. It is these kinds of proactive collaborations that can, and will over time, engender a conscious educational paradigm shift from reactive toward predictive approaches to disaster risk reduction. As other sciences have been successfully incorporated into disaster management programs, climate science cannot remain siloed but must be incorporated to assist with the evolution and efficacy of the field.

\section{ACKNOWLEDGEMENT}

The authors would like to thank M.D Ricardo Suarez Bustamante, Comprehensive Expert in Science, Technology and the Environment (CITMA) in Baracoa, Cuba for his insights into Cuba's Tarea Vida strategy. 


\section{REFERENCES}

[1] Kelman, I., Gaillard, J. \& Mercer, J., Climate change's role in disaster risk reduction's future: Beyond vulnerability and resilience. International Journal of Disaster Risk Science, 6(1), pp. 21-27, 2015.

[2] Mall, R., Srivastava, R., Banerjee, T., Mishra, O., Bhatt, D. \& Sonkar, G., Disaster risk reduction including climate change adaptation over South Asia: Challenges and ways forward. International Journal of Disaster Risk Science, 10(1), pp. 14-27, 2018.

[3] Fema.gov, Biggert Waters Flood Insurance Reform Act of 2012: Impact of National Flood Insurance Program (NFIP) Changes, 2019. www.fema.gov/media-librarydata/20130726-1909-25045-0554/bw12_sec_205_207_factsheet4_13_2013.pdf. Accessed on: 29 Mar. 2019.

[4] Gao.gov, High Risk: National Flood Insurance Program, 2019. www.gao.gov/highrisk/national flood insurance/why did study\#t=1. Accessed on: 29 Mar. 2019.

[5] Haddow, G., Bullock, J. \& Coppola, D., Introduction to Emergency Management, pp. $1-2,2017$.

[6] Oregon Department of Geology and Mineral Industries, DOGAMI open file report series. www.oregongeology.org/pubs/ofr/p-O-18-02.htm. Accessed on: 15 May 2019.

[7] Wang, Y., Steven, B. \& Scott, M., Earthquake risk study Oregon's critical energy infrastructure hub, Oregon.gov, 2013. www.oregon.gov/energy/safety-resiliency/ Documents/2013\%20Earthquake\%20Risk\%20Study\%20in\%20Oregon's\%20Critical \%20Energy\%20Infrastructure\%20Hub.pd. Accessed on: 15 May 2019.

[8] ShakeAlert ${ }^{\mathbb{R}}$, Earthquake early warning. www.shakealert.org. Accessed on: 15 May 2019.

[9] USGS, Program VH, Cascades Volcano Observatory. https://volcanoes.usgs.gov/observatories/cvo/cascade_volcanoes.html. Accessed on: 15 May 2019.

[10] Stott, P.A. et al., Attribution of extreme weather and climate-related events. Wiley Interdisciplinary Reviews: Climate Change, 7, pp. 23-41, 2016.

[11] Internal Displacement Monitoring Centre, Global report on internal displacement (GRID) 2019. www.internal-displacement.org/global-report/grid2019/. Accessed on: 29 May 2019.

[12] NOAA, Climate information. www.ncdc.noaa.gov/climate-information.

[13] A short introduction to climate models - CMIP \& CMIP6. www.wcrp-climate.org/ wgcm-cmip/cmip-video. Accessed on: 21 May 2019.

[14] IPCC, About the IPCC. www.ipcc.ch/about/. Accessed on: 21 May 2019.

[15] NCA, Fourth National Climate Assessment - Volume II: Impacts, Risk, and Adaptation in the United States. https://nca2018.globalchange.gov. Accessed on: 21 May 2019.

[16] Climate.gov., Science and Information for a Climate-Smart Nation. www.climate.gov. Accessed on: 21 May 2019.

[17] National Hurricane Center and Central Pacific Hurricane Center, www.nhc.noaa.gov/?atlc. Accessed on: 21 May 2019.

[18] Advancing Global NWP through International Collaboration, https://www.ecmwf.int. Accessed on: 21 May 2019.

[19] Regional Climate Centers, www.ncdc.noaa.gov/customer-support/partnerships/ regional-climate-centers. Accessed on: 21 May 2019.

[20] Physical Sciences Division, Physical Science for Predicting Extremes. www.esrl.noaa.gov/psd/. Accessed on: 21 May 2019. 
[21] NOAA National Centers for Environmental Information: Data Access, www.ncdc.noaa.gov/data-access. Accessed on: 21 May 2019.

[22] Eyring, V. et al., Overview of the coupled model intercomparison project Phase 6 (CMIP6) experimental design and organization. Geoscientific Model Development, 9, pp. 1937-1958, 2016.

[23] Ministerio de Ciencia, Tecnología y Medio Ambiente (Cuba). www.ecured.cu/Ministerio_de_Ciencia_Tecnología_y_Medio_Ambiente. Accessed on: 22 Mar. 2019.

[24] Civil Defense Cuba, Editor's note quote from Division General Ramon Pardo Guerra, Chief of the National Civil Defense Headquarters, p. 1, 2018.

[25] Green Climate Fund, Coastal adaptation to climate change in Cuba through ecosystem based adaptation. Republic of Cuba, United Nations Development Programme (UNDP), p. 9, 2018.

[26] World Bank Database, Physicians per 1,000 people.

https://data.worldbank.org/indicator/SH.MED.PHYS.ZS?end=1974\&locations=CU\& start=1974\&view=map\&year=2014\&year_high_desc=false. Accessed on: 22 Mar. 2019.

[27] Davila, W., Highly powerful hurricanes: Protecting the population and its assets in Cuba. Civil Defense Cuba, 1, p. 5, 2018.

[28] UNDP, A Cuban model for a resilient Caribbean. www.undp.org/content/undp/en/ home/presscenter/articles/2015/02/25/a-cuban-model-for-a-resilient-caribbean.html. Accessed on: 22 Mar. 2019.

[29] Gibara Response to Hurricane Ike and Matthew Interview with M.D. Bustamante, Baracoa, Cuba, 2018.

[30] ¡ahora!, Redacción. Tarea Vida with Remarkable Results in Holguín. www.ahora.cu/en/holguin/1967-tarea-vida-with-remarkable-results-in-holguin. Accessed on: 31 Mar. 2019.

[31] Huang, S.-K., Lindell, M.K., Prater, C.S., Wu, H.-C. \& Siebeneck, L.K., Household evacuation decision making in response to Hurricane Ike. Natural Hazards Review, 13(4), pp. 283-296, 2012.

[32] Morrs, R.E. \& Hayden, M.H., Storm surge and "certain death": Interviews with Texastavb coastal residents following Hurricane Ike. Weather, Climate, and Society, 2, pp. 174-189, 2010. 